\title{
Launching the Idea Corners section of Marketing Letters
}

\author{
Peter N. Golder ${ }^{1} \cdot$ Sandy D. Jap ${ }^{2}$
}

Published online: 9 March 2020

(C) Springer Science+Business Media, LLC, part of Springer Nature 2020

We are delighted to launch the publication of a new article format for Marketing Letters, indeed a new format for the entire marketing discipline: 1500-word articles identifying novel marketplace phenomena and their resulting research opportunities. These articles bring marketing's unique perspective to bear on vital new phenomena for the benefit of businesses and society at large. We will not attempt to summarize the initial set of six articles here, but we are sure that you will be intrigued by the topicsspeciesism, "clicks and bricks" retailing, the second digital revolution, drug influences on consumer judgments, the cannabis industry, and price premia in producers' direct sales channels.

The Idea Corner article format is a contemporary manifestation of Don Lehmann's original vision for Marketing Letters: to explore novel, interesting, provocative research topics and quickly disseminate those ideas to the field in order to spark debate, discussion, and new research. We believe that the set of Idea Corner articles in this issue fulfills that vision. Please see our 2017 editorial (co-authored with former editor, Joel Steckel) for a more detailed description of this article format. These new 1500word articles complement and will be published alongside the journal's traditional 5000-word articles. In our editorial (p. 336), we described 'an 'idea' as an initial thought, intended to stimulate or presage future research and a 'corner' as a point at which significant change occurs." These short papers are designed to lower the cost to authors for sharing their discoveries of important, novel phenomena with the field as well as for enhancing the accessibility of these ideas to researchers across our discipline.

Peter N. Golder

Peter.N.Golder@tuck.dartmouth.edu

Sandy D. Jap

SJAP@emory.edu

1 Dartmouth College, Hanover, NH, USA

2 Emory University, Atlanta, GA, USA 
The review process for Idea Corner papers is streamlined to ensure another key principle of Marketing Letters: papers belong to authors, not reviewers or editors. A short review is provided by the editor and one additional reviewer, with a decision of conditional acceptance or rejection after this initial review. The streamlined review process for Idea Corner papers, as well as regular submissions to Marketing Letters, is aimed to provide an alternative to the increasingly protracted review process at other journals, freeing up authors' and reviewers' scarce time for generating and disseminating even more research insights. Indeed, "[t]he advancement of our field rests upon generating interesting, provocative ideas and getting those ideas into the marketplace rapidly in order to be debated, tested, refined, and sometimes rejected" (Golder et al. 2017, p. 339). Marketing Letters remains committed to these ideals.

\section{Reference}

Golder, P. N., Jap, S., \& Steckel, J. H. (2017). The future of Marketing Letters: vision, review process, and a new type of paper-idea corners. Marketing Letters, 28, 335-339.

Publisher's note Springer Nature remains neutral with regard to jurisdictional claims in published maps and institutional affiliations. 